\title{
A process for deriving high quality cellulose nanofibrils from water hyacinth invasive species
}

\author{
Dongyang Sun (i) - Amaka J. Onyianta (D) Dominic O'Rourke • Guilhem Perrin • \\ Carmen-Mihaela Popescu $\cdot$ Lip Huat Saw $\cdot$ Zuansi Cai $\cdot$ Mark Dorris
}

Received: 23 August 2019/Accepted: 1 February 2020/Published online: 12 February 2020

(C) The Author(s) 2020

\begin{abstract}
In this study, surface chemistry, the morphological properties, water retention values, linear viscoelastic properties, crystallinity index, tensile strength and thermal properties of water hyacinth (WH) cellulose were correlated with the degree of mechanical processing under high-pressure homogenisation. An initial low-pressure mechanical shear of WH stems resulted in the ease of chemical extraction of good quality cellulose using mild concentrations of chemical reagents and ambient
\end{abstract}

Electronic supplementary material The online version of this article (https://doi.org/10.1007/s10570-020-03038-4) contains supplementary material, which is available to authorized users.

D. Sun · A. J. Onyianta ( $₫)$ · D. O'Rourke · G. Perrin · M. Dorris

Nanomaterial Unit, School of Engineering and Built Environment, Edinburgh Napier University,

Edinburgh EH10 5DT, UK

e-mail: a.onyianta@napier.ac.uk

D. Sun

e-mail: d.sun@napier.ac.uk

D. O'Rourke

e-mail: d.orourke@napier.ac.uk

M. Dorris

e-mail: m.dorris@napier.ac.uk

C.-M. Popescu

Petru-Poni Institute of Macromolecular Chemistry of the

Romanian Academy, Bucharest, Romania

e-mail: mihapop@icmpp.ro temperature. Further passes through the homogeniser resulted in an overall improvement in cellulose fibrillation into nanofibrils, and an increase in water retention property and linear viscoelastic properties as the number of passes increased. These improvements are most significant after the first and second pass, resulting in up to $7.5 \%$ increase in crystallinity index and $50 \%$ increase in the tensile strength of films, when compared with the unprocessed WH cellulose. The thermal stability of the WH cellulose was not adversely affected but remained stable with increasing number of passes. Results suggest a high suitability for this process to generate superior quality cellulose nanofibrils at relatively low energy requirements, ideal

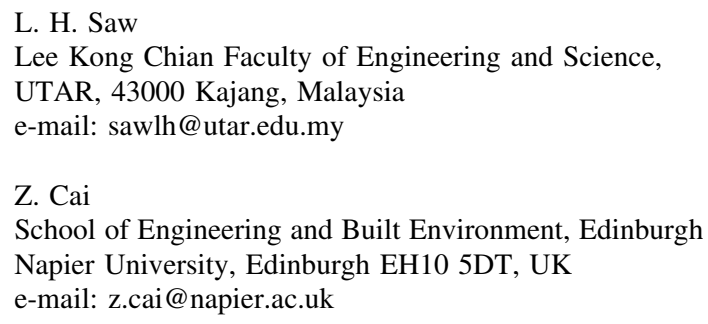

L. H. Saw

Lee Kong Chian Faculty of Engineering and Science, UTAR, 43000 Kajang, Malaysia e-mail: sawlh@utar.edu.my

Z. Cai

School of Engineering and Built Environment, Edinburgh Napier University, Edinburgh EH10 5DT, UK

e-mail: z.cai@napier.ac.uk 
for sustainable packaging applications and as a structural component to bioplastic composite formulations.

Keywords Cellulose nanofibrils (CNF) - Water hyacinth stems - Morphological properties .

Viscoelastic properties - Water retention values (WRV)

\section{Introduction}

Amongst the naturally occurring polymers, cellulose has gained extensive popularity for various potential applications due to its availability and abundance in nature. Found in wood, plants, some bacteria and algae (Siró and Plackett 2010) cellulose is a polysaccharide constituted of linear chains, in which d-pyran glucose units (between several hundreds to over ten thousand) are compounded and linked by $\beta(1 \rightarrow 4)$ glycosidic bonding (Hon 1994). The cellulose elementary units align to form larger microfibrils and ultimately a cellulosic fibre matrix, within which hemicellulose and lignin are bound to the surface and entrapped within the microfibrils (Srivastava 2002).

The extraction of cellulose nanomaterials from various sources have been intensively reported because of the inherent biodegradable and biocompatible properties of this material (Klemm et al. 2018). In addition, the improved material properties such as reduced weight, increased strength, controllable optical properties, oxygen barrier properties and ability to form liquid crystals when going from the microscale to the nanoscale, have made the nanocellulose field an active research area (Lavoine et al. 2012; Jonoobi et al. 2015). Plant based sources that have been explored for cellulose extraction include hemp (Dai et al. 2013; Luzi et al. 2014), sugarcane bagasse (Mandal and Chakrabarty 2011; Rahimi Kord Sofla et al. 2019), wheat straw and soy hulls (Alemdar and Sain 2008), rice husk (Johar et al. 2012), wood flour (Li et al. 2016) pineapple leaf fibres (Cherian et al. 2010; Fareez et al. 2018), cotton (Al-khateeb et al. 2015; Theivasanthi et al. 2018), bamboo (Hu et al. 2014), kenaf bast (Karimi et al. 2014; Song et al. 2018), etc.

Water hyacinth (Eichhornia crassipes) is one of the most pervasive aquatic weeds, which is very adaptable to the environment and can grow quickly, producing 106 tonne (dry weight) per Hectare per year (Reddy and Debusk 1984). This plant is usually invasive and can have serious detrimental effects on the surrounding environment due to its rapid growth on water bodies in tropical regions. The water surface can be quickly covered, putting biodiversity in danger (Istirokhatun et al. 2015). Water hyacinth (WH) has low thermal energy and the combustion may produce secondary pollution. Huge sums of money are being spent worldwide to selectively remove the weeds by manual harvesting and use them as animal feed or for energy production (Gunnarsson and Petersen 2007).

Recently, WH have come under investigation as an alternative source for extracting cellulose/nanocellulose (Thiripura Sundari and Ramesh 2012; Suryadi et al. 2017; Asrofi et al. 2018; Juárez-Luna et al. 2019; Tanpichai et al. 2019). Most of these studies on cellulose extraction from WH make use of high amounts of alkali at elevated temperatures, up to $90{ }^{\circ} \mathrm{C}$ (Thiripura Sundari and Ramesh 2012; Suryadi et al. 2017). Juárez-Luna et al. (2019) applied a different approach by using cellulase enzymes instead of alkalis to extract cellulose nanoparticles from water hyacinth stems. Other methods that have been used to extract nanocellulose include acid hydrolysis (Istirokhatun et al. 2015), successive ball-milling, cryocrushing and sonication (Thiripura Sundari and Ramesh 2012), and high-intensity ultra-sonication (Hu et al. 2014; Asrofi et al. 2018). These studies focused on the extraction methods and property characterisation of the resulting cellulose at different stages of extraction, with no further processing to nanocellulose or characterisation thereof.

The use of high pressure microfluidic mechanical processors has been proven efficient for the fibrillation of cellulose materials into cellulose nanofibrils (Spence et al. 2011). In this study, a PSI-20 high pressure homogeniser ${ }^{\circledR}$, was used both as a pretreatment tool, to assist the extraction of cellulose from water hyacinth stems, and also for cellulose fibrillation into nano-sized material. An initial lowpressure processing pass of water hyacinth stems was carried out to help loosen the lignocellulosic matrix, which led to the facile extraction of cellulose at low alkali concentration and at room temperature. The changes in surface chemistry during the stages of extraction was studied by Fourier-transform infrared spectrophotometry. The impact of increasing number of passes through the mechanical processor on WH 
cellulose were studied through morphological analysis, water retention value studies and linear viscoelastic analysis, crystallinity index studies, tensile tests and thermal stability studies. These analyses help establish the properties of WH cellulose extracted herein and the optimum processing conditions required to produce good quality $\mathrm{CNF}$ that can find applications in composite formulations.

\section{Experimental procedure}

Raw materials and chemicals

Water hyacinth (WH) stems were collected from a local lake in Taman Tasik Seri Aman, Puchong, Malaysia. The WH stems were separated from the roots and leaves, washed and air dried for 3 days before being used for the cellulose extraction process. See Fig. 1a for photographic image of WH stems. Sodium hydroxide $(\mathrm{NaOH})$, hydrochloric acid $(\mathrm{HCl})$, sodium chloride $(\mathrm{NaCl})$, and sodium hypochlorite solution ( $\mathrm{NaClO}, 6-14 \%$ active chlorine) were received from Sigma-Aldrich, UK. Glacial acetic acid $\left(\mathrm{CH}_{3} \mathrm{COOH}\right)$ was received from Fisher Scientific, UK. All chemicals were reagent grade and used without further purification. Ultrapure water (Purelab Option$\mathrm{Q}$, Class 1 water system, ELGA) was used in all the experiments.

\section{WH slurry preparation and cellulose extraction}

The dried WH stems were crushed using a household blender and mixed with ultrapure water, forming $0.25 \mathrm{wt} \%$ slurry. The slurry was soaked overnight in water before being homogenised using a rotor-stator mixer (Ultra-turrax T25, IKA, UK) for approximately $10 \mathrm{~min}$ at 13,000 rpm. The material was then homogenised using a PSI-20 homogeniser (Adaptive Instruments, UK) through a $200 \mu \mathrm{m} \mathrm{Z}$-shaped interaction chamber at approximately 8000 psi. Afterwards, the slurry was centrifuged using Sorvall RC 6 Plus centrifuge (Thermo Scientific, UK) to remove excess water and recover WH pellets.

The cellulose extraction started with a bleaching process, in which the $\mathrm{WH}$ pellets were placed in a $\mathrm{NaClO}$ solution at room temperature and stirred overnight. The bleaching solution was prepared by mixing $\mathrm{NaClO}$ with ultrapure water at $1: 3$ weight ratio and adjusted to $\mathrm{pH}$ of 4 using glacial acetic acid. This was followed by a $\mathrm{NaOH}$ aqueous solution (1 wt \%) treatment at room temperature $\left(22{ }^{\circ} \mathrm{C}\right)$ for $2 \mathrm{~h}$ under

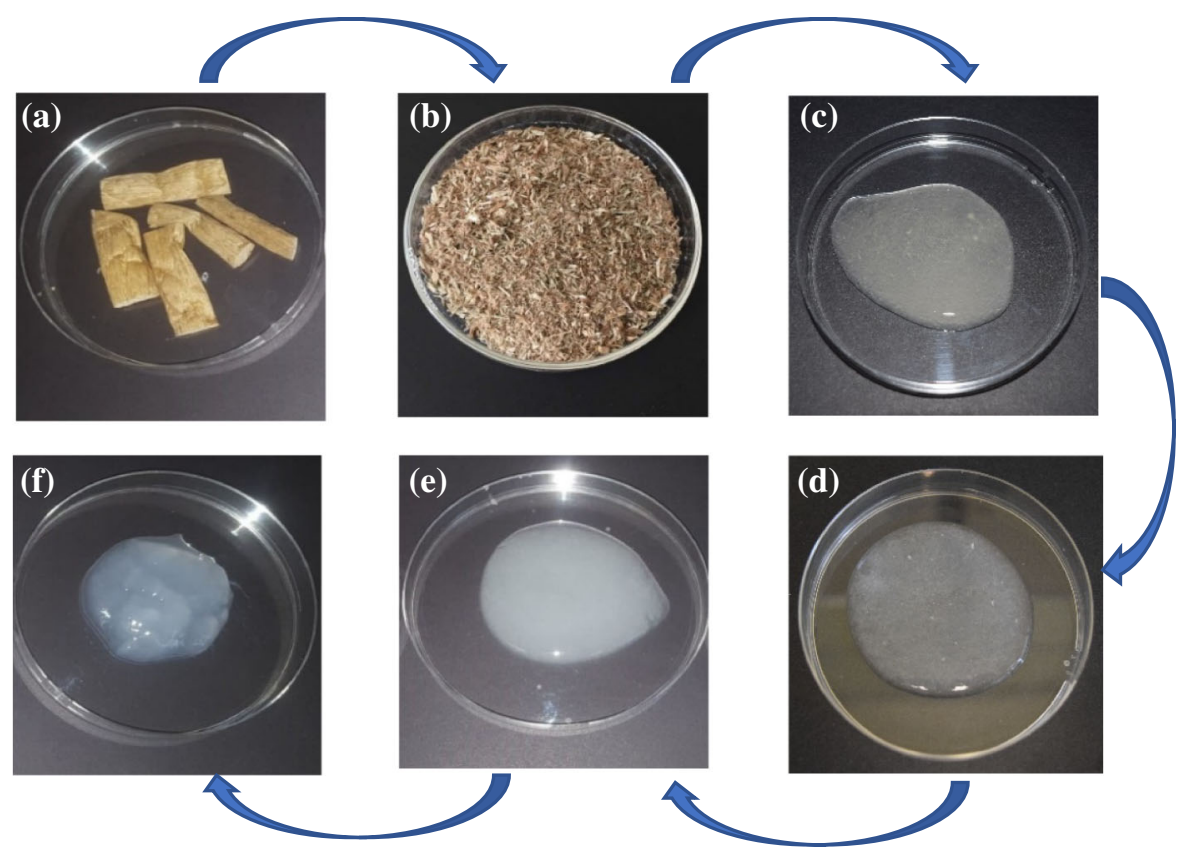

Fig. 1 Photographic images of WH scissors-cut stems (a), blended stems (b), WH after first bleaching (c), WH after NaOH (d), WH cellulose after second bleaching (e) and WH CNF gel-like material (f). All slurries are shown at $0.5 \mathrm{wt} \%$ 
continuous stirring. For further delignification, the lignocellulose material was subjected to another bleaching process, in the same $\mathrm{NaClO}$ solution as above, for $2 \mathrm{~h}$ under continuous stirring. The material was washed in ultrapure water between each step by successive centrifugation and decantation. The solid content of the washed sample was then determined by gravimetric analysis and the percentage yield of the extraction process was determined as the ratio of the weight of the cellulose material to the weight of dried stems. Finally, the cellulose material was diluted to form $0.5 \mathrm{wt} \%$ slurry for subsequent processing.

Mechanical processing of the extracted cellulose

The PSI-20 high homogeniser was additionally used for the fibrillation of $0.5 \mathrm{wt} \%$ aqueous cellulose dispersion to obtain cellulose nanofibrils (CNF). The cellulose material was passed 5 times through a $100 \mu \mathrm{m}$ Z-shape interaction chamber at 25,000 psi. Henceforth, 0 pass sample represents the extracted cellulose without any mechanical fibrillation, while 1-5 pass samples represent cellulose materials that have undergone mechanical fibrillation through the homogeniser for 1-5 times.

\section{Conductometric titration}

Conductometric titration was carried out using the method described in SCAN-CM 65:02 test method for total acidic group content (Scan-test 2002). The experiment was carried out at downscaled reagent quantities. In summary, the never dried cellulose pulp was dispersed in $0.1 \mathrm{M} \mathrm{HCl}$ and allowed to soak for $15 \mathrm{~min}$ before being washed with ultrapure water until the conductivity was less than $5 \mu \mathrm{S} / \mathrm{cm}$. The base $(0.05 \mathrm{M} \mathrm{NaOH})$ was standardised with $0.01 \mathrm{M}$ of $\mathrm{HCl}$ before using it as a titrant. $147 \mathrm{~mL}$ of ultrapure water and $3 \mathrm{~mL}$ of $0.05 \mathrm{M} \mathrm{NaCl}$ were added to $0.3 \mathrm{~g}$ dry weight of the protonated cellulose pulp in a beaker. The function of the $\mathrm{NaCl}$ was to improve the accuracy of the results. The mixture was stirred thoroughly using a magnetic stirrer until the conductivity and $\mathrm{pH}$ have equilibrated. The titration was started with the addition of $0.05 \mathrm{M} \mathrm{NaOH}$ at the rate of $100 \mu \mathrm{L} / \mathrm{min}$ until a $\mathrm{pH}$ of 10 was achieved. Titration was carried out in triplicate and the average total acidic content \pm standard deviation was reported.
Fourier transform infrared (FTIR)

spectrophotometric characterisation

An FTIR spectrophotometer (Spectrum 100, PerkinElmer, UK) was used to determine the functional groups of the cellulose samples during and after the extraction process. The cellulose samples obtained at various stages were dried into films and used to obtain the spectrum between the 4000 and $450 \mathrm{~cm}^{-1}$ range at $4 \mathrm{~cm}^{-1}$ resolution.

Field emission scanning electron microscopy (FESEM)

The surface morphology of $0-5$ pass samples were examined using S4800 FE-SEM, (Hitachi, Japan). Samples were homogenised and diluted to form $0.0001 \mathrm{wt} \%$ solution before being dropped on a freshly cleaved mica disc (muscovite, $9.9 \mathrm{~mm}$ diameter and $0.22-0.27 \mathrm{~mm}$ thickness, Agar Scientific, UK) that was attached on an FE-SEM aluminium stub.

The samples were dried before being gold coated for $90 \mathrm{~s}$ using a sputter coater (EMITECH K550X, Quorumtech, UK) and observed with the FE-SEM at $3 \mathrm{kV}$ acceleration voltage. Micrographs of the original cellulose and CNF materials were obtained at various magnifications that would allow for adequate observation and fibril measurements using ImageJ software (version 1.47, National Institutes of Health, USA).

Water retention values (WRV)

In order to indirectly evaluate the degree of fibrillation, the water retention values of the 0 pass to 5 pass samples were studied using $0.5 \mathrm{wt} \%$ slurries from never-dried samples. $50 \mathrm{~g}$ of the slurry was transferred into falcon tubes and subjected to a centrifugation process, using the method adopted from Cheng et al. (2010). The centrifugation process was carried out at $900 \mathrm{~g}$ centrifugal force for $30 \mathrm{~min}$. The supernatant was removed from the falcon tubes using a pipette and the material at the bottom was transferred in an aluminium drying boat. An oven heated to $105^{\circ} \mathrm{C}$ was used in drying the material. The weights of the samples before and after the drying process were recorded using a four-digit balance. The WRV was evaluated using Eq. (1) 
$W R V=\frac{W_{w e t}-W_{d r y}}{W_{d r y}} \times 100$

Here $W_{w e t}$ and $W_{d r y}$ are the weight of the wet slurry and the dried material, respectively. Three replicates were examined and an average WRV was obtained.

Linear viscoelastic measurements

The effects of the number of passes (1-5) on the linear viscoelastic properties of the water hyacinth derived cellulose were investigated using a serrated concentric cylinder geometry (24 mm inner diameter and $26 \mathrm{~mm}$ outer diameter) on AR-G2 rheometer (TA Instruments, USA). An initial peak hold test was carried out at a shear rate of $100 \mathrm{~s}^{-1}$ for $100 \mathrm{~s}$ to clear sample and loading history. This was followed by a time sweep carried out for $600 \mathrm{~s}$ at $50 \mathrm{rad} \mathrm{s}^{-1}$ and $0.1 \%$ strain to allow for sample recovery. Limited amplitude sweeps were then conducted at an angular frequency of $50 \mathrm{rad} \mathrm{s}^{-1}$ and a stress of 0.01-2.0 Pa to identify the linear viscoelastic region (LVR) for each sample. Frequency sweeps were then carried out at $0.1 \%$ strain from 50 to $0.5 \mathrm{rad} \mathrm{s}^{-1}$ to study the effects of the number of passes through the homogeniser on the storage modulus $\left(G^{\prime}\right)$ and loss modulus $\left(G^{\prime \prime}\right)$. Samples were tested at $0.5 \mathrm{wt} \%$ in triplicates and the average data \pm standard deviation were reported.

\section{X-ray diffraction (XRD)}

The X-ray diffraction patterns were recorded with a Bruker D8 Advance X-ray diffractometer (Germany) by using $\mathrm{Cu}-\mathrm{K}$ radiation $(\lambda=0.1542 \mathrm{~nm})$, a parallel beam with Gobel mirror and a Dynamic Scintillation detector. The accelerating voltage was of $40 \mathrm{kV}$, the current of $30 \mathrm{~mA}$ and scanning range between $5^{\circ}$ and $40^{\circ}(2 \theta)$.

In order to calculate the crystallinity degree, the Xray diffractograms were deconvoluted with mixed Gaussian-Lorenzian (crystalline regions) and Voight profiles (amorphous background). After the deconvolution, the crystallinity degree was calculated with Eq. 2, proposed by Hermans and Weidinger (1948) and later used by many other researchers (Popescu et al. 2007; Mendoza et al. 2019)

Cr.I. $\%=\frac{A_{c}}{A_{t}} * 100$
Here: Cr.I.\% is the crystallinity degree, $A_{\mathrm{c}}$ is the crystalline area obtained by the sum of signal areas (110), (110), (200), (102) and (004), and $A_{\mathrm{t}}$ is the total area.

Preparation of WH cellulose films and tensile strength testing

The $0.5 \mathrm{wt} \%$ slurries as described above were used for preparing the films. The dispersion was diluted, poured into a plastic petri dish and air-dried under laboratory fume cupboards. Slurries in each petri-dish contain $0.02 \mathrm{~g}$ of cellulose to ensure consistency of film thickness. After drying, the films were removed from the dish and cut into strips of approximately $15 \mathrm{~mm}$ wide for a tensile test using Lloyd LRX Tensile Test Machine (Lloyd Instruments, UK), with a load cell of $100 \mathrm{~N}$. The strips were placed between two jaws of $25 \mathrm{~mm}$ apart and pulled at a crosshead speed of $1 \mathrm{~mm} / \mathrm{min}$. The morphology of a representative film and its thickness (for cross-section area calculation) can be found in Fig. S1 of the supplementary document. A minimum of 5 strips per sample were tested and the average data \pm standard deviation were reported. The stress-strain curves of representative replicates are shown in Fig. S2.

Thermogravimetric analysis (TGA)

Thermogravimetric analyses were conducted on the extracted WH cellulose and the processed samples to determine the thermal behaviour of WH cellulose and the effect of the mechanical shearing on the processed samples. TGA was carried out using Mettler Toledo TGA/DSC1 Star System (Mettler Toledo, Switzerland). Approximately $10 \mathrm{mg}$ of samples were heated from 25 to $600{ }^{\circ} \mathrm{C}$ at a constant heating rate of $10{ }^{\circ} \mathrm{C} /$ min under a constant nitrogen flow of $80 \mathrm{~mL} / \mathrm{min}$.

\section{Results and discussion}

\section{Extraction of cellulose from WH}

Room temperature $\left(22^{\circ} \mathrm{C}\right)$ was sufficient for the cellulose extraction of processed WH stems using $\mathrm{NaOH}$. Previous cellulose extraction attempts in $\mathrm{NaOH}$ at higher temperatures resulted in cellulose 
hydrolysis. The second bleaching process was used to further remove any remaining lignin in the material. Figure 1 shows the cellulose samples at various treatment stages. The brown coloured dried stems of WH and the blended stems are shown in Fig. 1a, b respectively. The resultant white coloured cellulose material from the extraction process is shown in Fig. 1c-e depicting the cellulose slurry after the first bleaching, $\mathrm{NaOH}$ treatment, and second bleaching respectively. The colour change is attributed to the removal of hemicellulose and delignification of $\mathrm{WH}$ fibres during the bleaching process using acidified $\mathrm{NaClO}$ and treatment with $\mathrm{NaOH}$ (Osong et al. 2016). The mechanically fibrillated translucent and gel-like sample is shown in Fig. 1f.

The yield of the extraction process was $19.38 \% \pm 0.59 \%$. This yield is reasonable considering the chemical composition in water hyacinth that are commonly reported as $20-25 \%$ of cellulose, 30 $35 \%$ of hemicellulose, $5-10 \%$ of lignin and $5-10 \%$ of ash (Istirokhatun et al. 2015; Guna et al. 2017). It is therefore anticipated that the hemicellulose and lignin contents in the raw material used in this study fall within the reported range. The viscosity average degree of polymerisation $(D P v)$ was estimated to be 309 and fully presented in Section S1 of the supplementary document.

Surface chemistry analyses of extracted cellulose by conductometric titration and FTIR

The total acidic groups content of the extracted cellulose was $131 \pm 3 \mu \mathrm{mol} / \mathrm{g}$. The total acidic groups of wood pulps reported have been reported to be $30 \mu \mathrm{mol} / \mathrm{g}$ and $44 \mu \mathrm{mol} / \mathrm{g}$ by Onyianta et al. (2018a) and Pääkko et al. (2007) respectively. Although the total acidic groups content of $\mathrm{WH}$ cellulose is not considered significant, its presence may be attributed to the double sodium hypochlorite bleaching process, known to partially oxidise the cellulose hydroxyl groups to aldehyde/carboxylic acid groups (Someshwar and Pinkerfon 1992). Alternatively, the acidic groups may be attributed to the uronic acid component of remaining hemicellulose in the sample.

Functional group analyses were performed at different stages of extraction from the FTIR spectra shown in Fig. 2. All the cellulose peak intensities increased after the $\mathrm{NaOH}$ and second bleaching treatments as the hemicellulose and lignin materials are removed. The major cellulose characteristic peaks are observed at $3330 \mathrm{~cm}^{-1}, 2894 \mathrm{~cm}^{-1}, 1630 \mathrm{~cm}^{-1}$ and $1027 \mathrm{~cm}^{-1}$, originating from the stretching of $\mathrm{OH}$ groups $\mathrm{C}-\mathrm{H}$ stretching, $\mathrm{O}-\mathrm{H}$ bending from chemically adsorbed water in the amorphous region and $\mathrm{C}-\mathrm{O}$ stretching (Chung et al. 2004). The magnified region in Fig. 2 shows the disappearance of two peaks at $1735 \mathrm{~cm}^{-1}$ and at $1240 \mathrm{~cm}^{-1}$ after the $\mathrm{NaOH}$ treatment. The $1735 \mathrm{~cm}^{-1}$ was assigned to acetyl and uronic ester groups of hemicelluloses or to the ester linkage of carboxylic group of the ferulic and p-coumaric acids of lignin, while the peak at $1240 \mathrm{~cm}^{-1}$ was assigned to ether, phenols or esters of lignin (Cherian et al. 2008; Tibolla et al. 2018). The total acidic group identified from conductometric titration for the cellulose sample obtained after the second bleaching step may not have been high enough to be identified by FTIR. These peaks usually appear at $1730-1740 \mathrm{~cm}^{-1}$ for carboxylic acid or $1590-1600 \mathrm{~cm}^{-1}$ for sodium carboxylate groups (Onyianta et al. 2018b).

\section{Morphological analysis}

Micrographs in Fig. 3 show the microstructure of the cellulose sample that has undergone the bleaching and alkaline treatments. Bundles of microfibers, having a size of approximately $30 \mu \mathrm{m}$ in diameter, can be seen from the FE-SEM images. Through the extraction process, lignin, hemicellulose and other organic substances were removed/hydrolysed, and as a result the original plant was broken into bundles of fibres.

Figure 4 demonstrates the evolution of the microstructure in cellulose samples after being subjected through the homogeniser for various number of cycles (passes). During the fibrillation process using the PSI-20 high homogeniser, the material passes through a Z-shape interaction chamber $(100 \mu \mathrm{m}$ in diameter) at approximately $400 \mathrm{~m} / \mathrm{s}$, where a significant amount of shear force was applied to the cellulose fibres. Fibrils of reduced diameter were then peeled away from the fibres.

As the number of passes is increased, a higher degree of fibrillation of cellulose fibres was achieved. For example, in the 2 and 3 pass samples (Fig. 4b, c respectively), fibres of reduced diameter (several hundred $\mathrm{nm}$ ) as well as microfibers were still present. After 4 passes (Fig. 4d), a reasonable amount of 


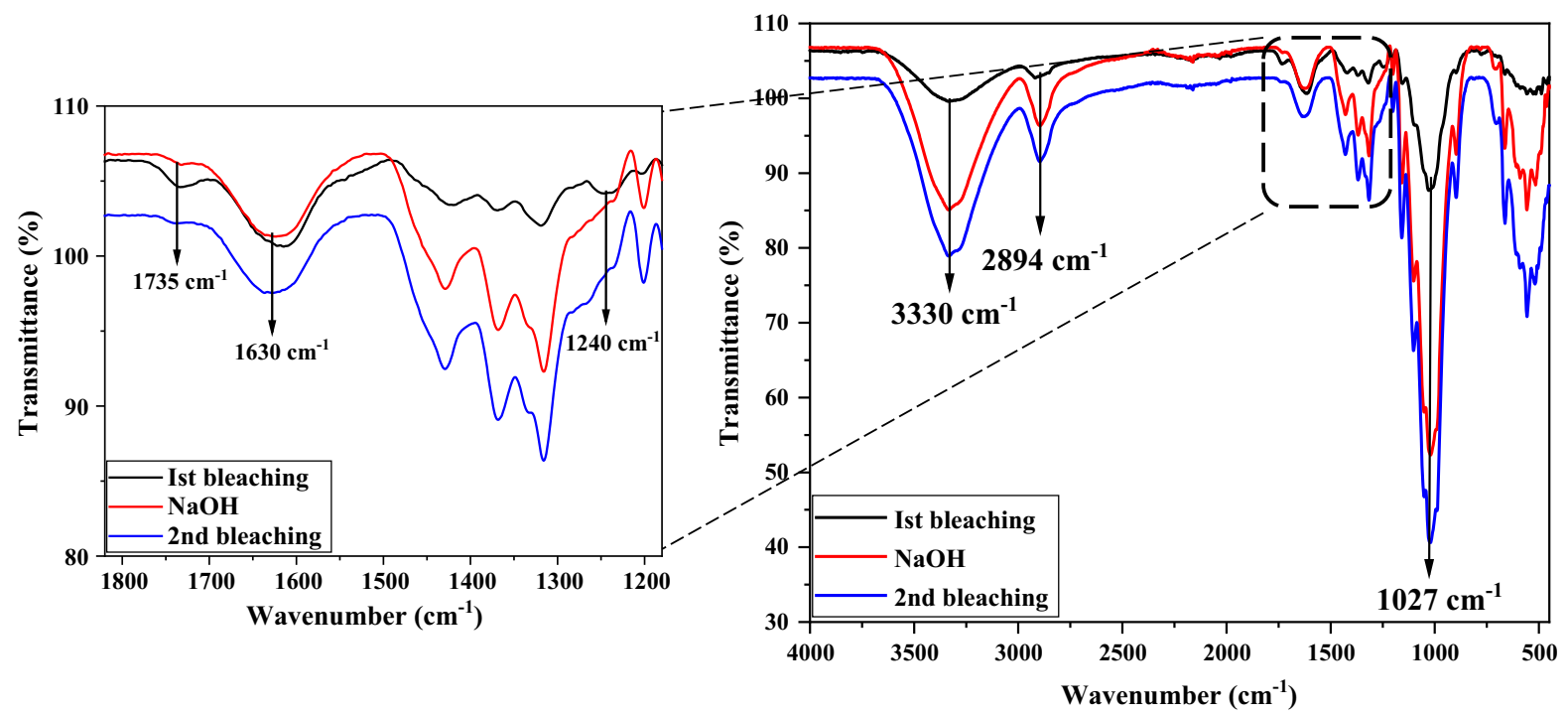

Fig. 2 FTIR spectra of WH cellulose at different stages of chemical extraction. The magnified region shows the disappearance of hemicellulose $\left(1735 \mathrm{~cm}^{-1}\right)$ and lignin $\left(1240 \mathrm{~cm}^{-1}\right)$ peaks

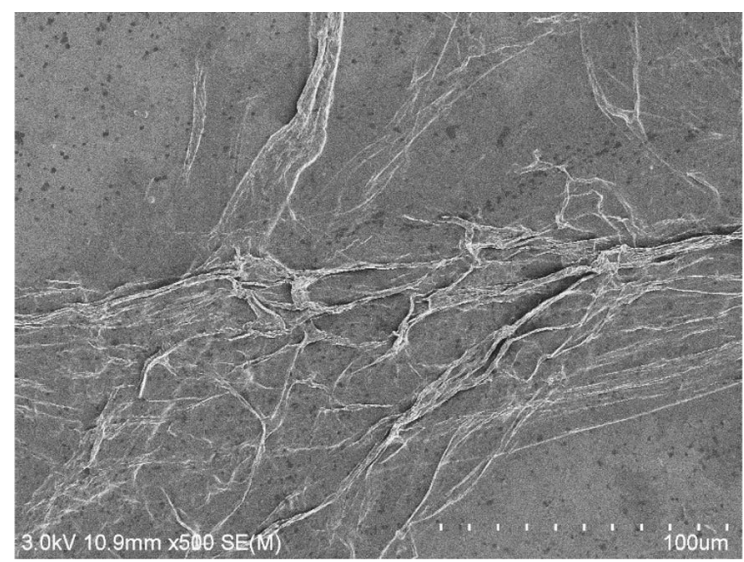

Fig. 3 Microstructure of WH fibres after the extraction process at $\times 500$ magnification

cellulose fibres has been delaminated to the nanoscale, resulting in the formation of individualised nanofibrils. It was observed that after 5 passes Fig. 4e, most fibrils are in the nanoscale, indicating that the processing of cellulose nanofibrils have been completed.

Figure $4 \mathrm{f}$ shows the magnified image of cellulose nanofibrils after 5 passes. The long nature of the fibrils alongside the drying process prior to image examination, resulted in fibril aggregation and the formation of a web-like network structure. This is similar with the morphology of cellulose samples reported elsewhere
(Chen et al. 2011; Chinga-Carrasco 2011; Qua et al. 2011).

The width of individual fibrils from the 5 pass sample was measured and the distribution summarised in Fig. 5. The histogram evidenced that the width distribution is asymmetrical and in the range between 10 and $35 \mathrm{~nm}$ approximately. The mean fibril width is $19.2 \pm 4.3 \mathrm{~nm}$. The long nature of the fibrils could not allow the measurement of lengths; however, this is estimated to be in the order of several micrometres.

Water retention values

The WRV is used to examine the capability of cellulose to retain water after centrifugation under standard conditions. Cellulose has high hygroscopicity due to the interaction of its hydroxyl groups with water molecules (Cheng et al. 2010). When cellulose materials are subjected to the homogeniser, the WRV increases as the number of passes increases. This is due to individual fibrils formed through fibrillation process, increasing the total surface area and as a result more hydroxyl groups become accessible to interact with water molecules. Therefore, it is believed that WRV can be used to indirectly evaluate the degree of fibrillation for cellulose materials.

Figure 6 shows the WRV of 0 to 5-pass samples, where a linear trend was observed as the degree of mechanical processing increased. Evidently, a 
(a)

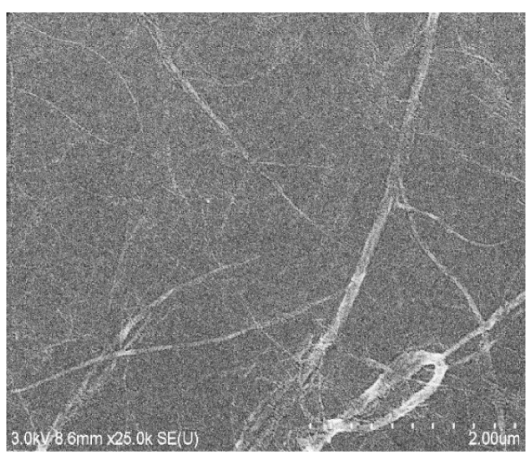

(c)

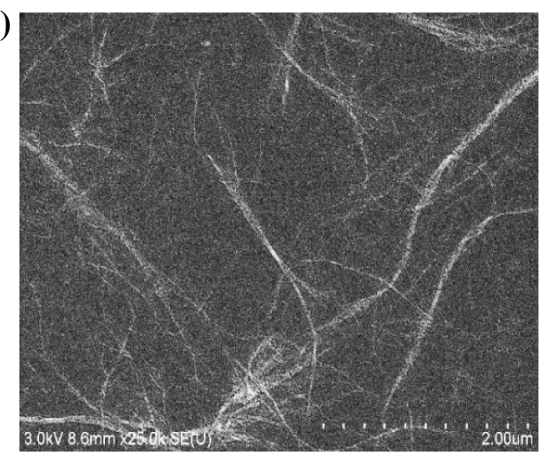

(e)

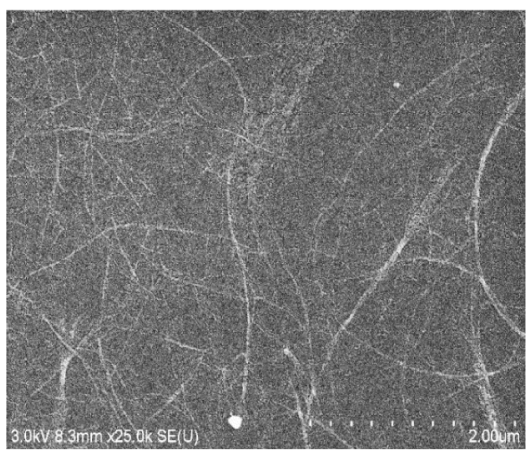

(b)

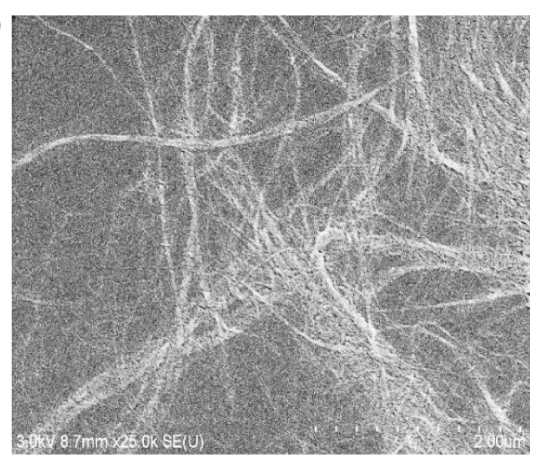

(d)

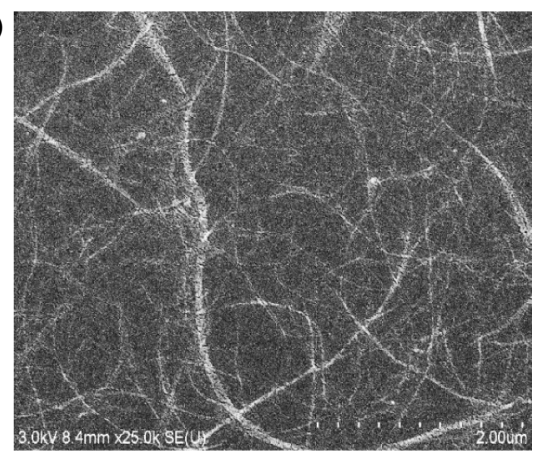

(f)

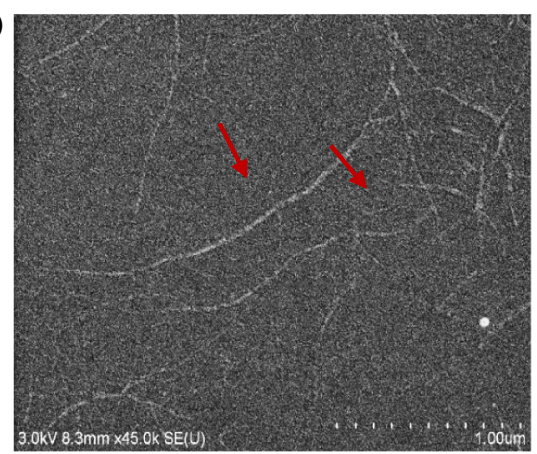

Fig. 4 Microstructure of cellulose samples after being subjected through the homogeniser from 1 pass to 5 pass in (a-e). $\mathbf{f}$ shows the magnified micrograph of cellulose nanofibrils from 5 pass sample (the arrow indicates individual fibrils)

significant increase in WRV can be seen from 0 to 1-pass, as the WRV is more than doubled from approximately $6000-12,700 \%$. This indicates that the fibrillation process in the first pass through the highpressure homogeniser is substantial, as the fibre bundles started delaminating into smaller sub-units. This is consistent with the observation from SEM micrographs. The significant delamination of fibres would dramatically increase the surface area of the cellulose material thus resulting in the large increase of WRV.

The WRV increase rate is reduced from 2 pass onwards. This indicates that the impact of the mechanical process on the fibrillation of cellulose materials is being stabilised and begins to tend towards saturation. This can be reasonably explained by the fibrillation process. As processing proceeds, larger sized fibres are fibrillated until a stage when (at least the majority of) individual units are hardly delaminated any further under the fixed mechanical conditions. Therefore, it can be predicted that even if the samples were to be processed further (e.g. 6 pass onwards), there wouldn't be any substantial increase of WRV. 


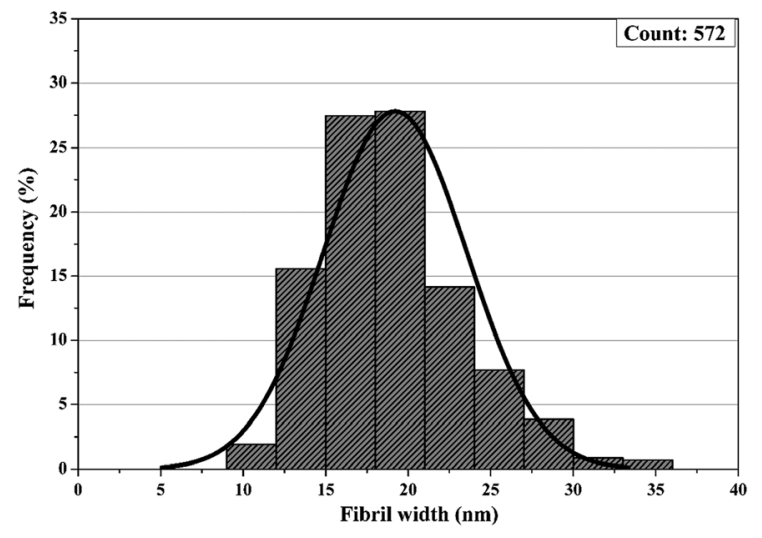

Fig. 5 Fibril width distribution of cellulose nanofibril after being processed for 5 passes in the homogeniser

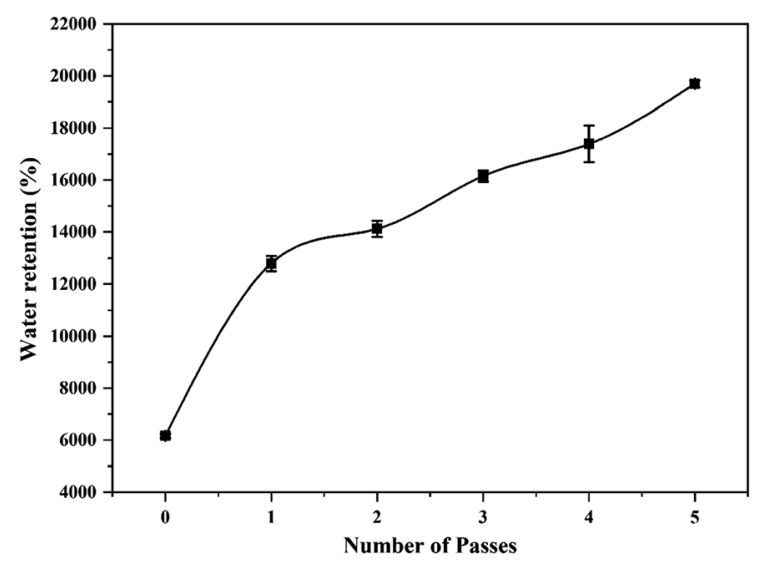

Fig. 6 WRV of the extracted cellulose (0p) and cellulose samples after $1-5$ passes

Effects of the number of passes on the viscoelastic properties of the water hyacinth cellulose

The degree of processing is one of the factors that affect the linear viscoelastic behaviour of $\mathrm{CNF}$ alongside $\mathrm{CNF}$ concentration and surface properties, whether modified or unmodified (Nechyporchuk et al. 2014). In this study, the effect of the number of passes of water hyacinth cellulose, at $0.5 \mathrm{wt} \%$, on the storage modulus and loss modulus was investigated by conducting amplitude sweeps and frequency sweeps. Non-mechanically processed cellulose samples could not be analysed for viscoelastic properties because of intense fibril aggregation and apparent wall slip at the concentration studied.

The results from the amplitude sweeps and frequency sweeps of 1 pass to 5 pass samples are presented in Figs. 7 and 8 respectively. A limited range of strain values was used during the amplitude sweep to avoid complete deformation of the samples, so that the materials can fully return to the linear viscoelastic region before the frequency sweep. All the samples studied showed a higher storage modulus than loss modulus. In addition, the storage moduli from the frequency sweeps were relatively independent of angular frequency. These are all indications of a prevalent solid-like material (Nechyporchuk et al. 2016; Onyianta et al. 2018b). It can be seen from both Figs. 7 and 8 that by increasing the number of passes through the high pressure homogeniser, the storage modulus increases.

The impact of the processing degree can be expressly seen from Fig. 9 as summarised from the frequency sweeps at $50 \mathrm{rad} \mathrm{s}^{-1}$ and $0.1 \%$ strain. A linear and greater increase in storage modulus is seen upon increasing the number of passes from 1 to 3 passes. This is as a result of the increase fibrillation into micro/nano sizes as the number passes increases, as has been shown from FE-SEM image analysis and water retention values. However, a more gradual and smaller increase was observed from the third pass to the fifth pass.

There is currently no consensus on the rheological behaviour (linear viscoelastic and shear viscosity behaviours) of cellulose nanofibrils upon increase in processing conditions. Onyianta (2019) observed a linear increase on the storage modulus of morpholine pre-treated wood cellulose upon increasing the

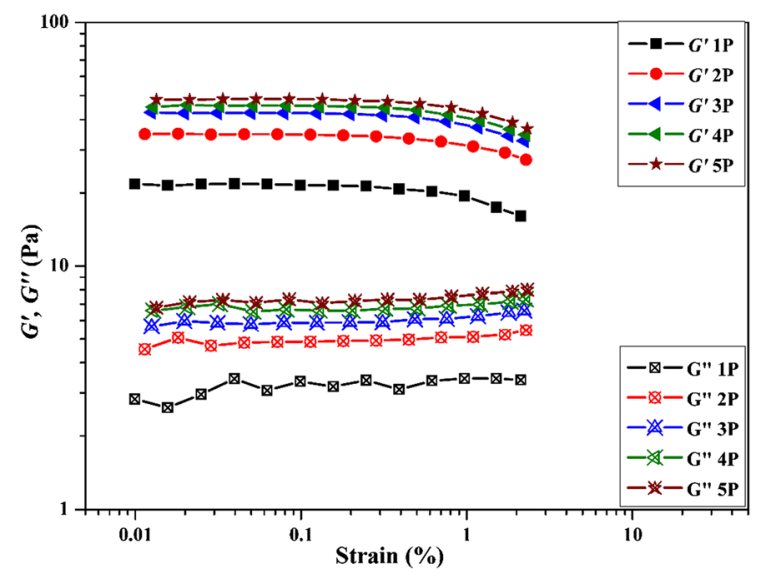

Fig. 7 Overlay of amplitude sweeps measurements on 1-5 pass WH cellulose. $G^{\prime}$ and $G^{\prime \prime}$ represent storage modulus and loss modulus. " $1 \mathrm{P}$ " represent 1-pass sample, etc 


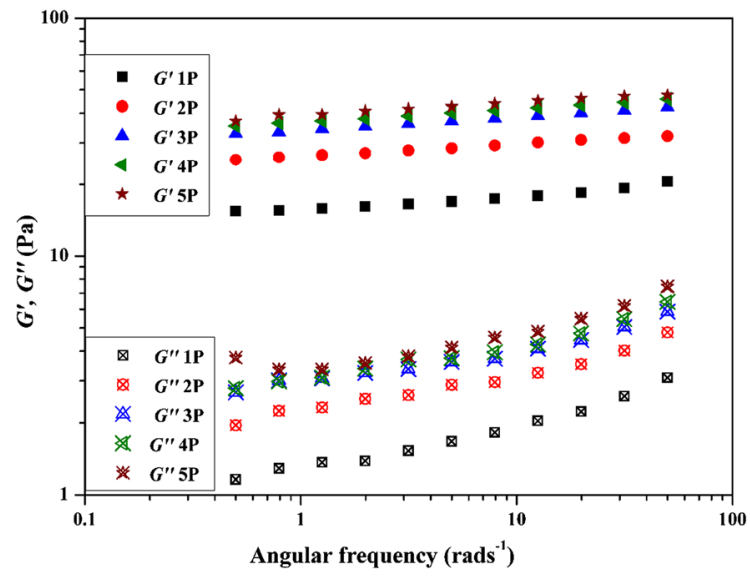

Fig. 8 Overlay of frequency sweeps measurements on 1-5 pass WH cellulose. $G^{\prime}, G^{\prime \prime}$ and "P" retain their meanings as in Fig. 7

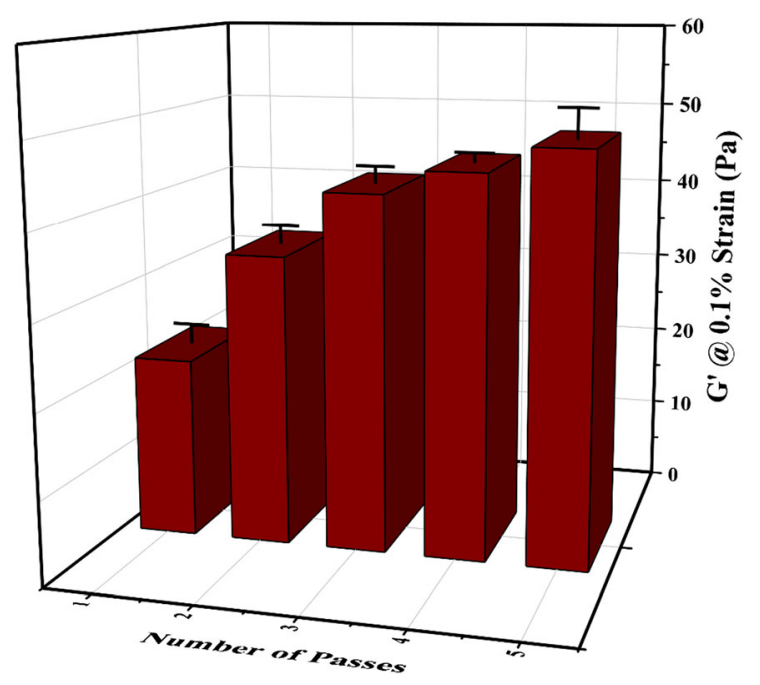

Fig. 9 Effect of the number of mechanical fibrillations on the storage modulus of $\mathrm{WH}$ cellulose. Data extracted from frequency sweeps at $50 \mathrm{rad} \mathrm{s}^{-1}$

number of passes from 1 to 5 . However, the same raw cellulose material when surface modified resulted in an initial increase in viscoelastic property from 1 to 2 passes before a decline was observed from 3 pass onwards (Onyianta 2019). Shogren et al. (2011) also reported similar trend of an initial increase in viscosity of CNF from corn cobs up to the second pass and a decline with further processing. Therefore, the effect of processing degree on rheological properties of CNF depends on the cellulose surface properties, source of cellulose, processing parameters, type of processor and the solid content used during processing.
Impact of mechanical processing

on the crystallinity index of WH cellulose

The X-ray diffractograms for samples of 0 pass to 5 passes are presented in Fig. 10. The XRD analysis permits the detection of the crystalline planes in the cellulose structure. Native cellulose or cellulose I presents five crystalline planes at about $14.5^{\circ}, 16.5^{\circ}$, $20.7^{\circ}, 22.2^{\circ}$ and $34.5^{\circ}$ corresponding to the $(1-10)$, (110), (102) (200) and (004) crystallographic planes (Popescu et al. 2012; Tarchoun et al. 2019).

As can be observed, all samples exhibit similar characteristic peaks at $2 \theta=15.7^{\circ}$ and $22.2^{\circ}$ representing the (110) and (200) crystallographic planes in the monoclinic cellulose I lattice (Nishiyama 2009). The other two peaks from $2 \theta=16.8^{\circ}$ and $20.3^{\circ}$ were identified only after deconvolution due to their overlapping with the previous mentioned peaks. The result indicates that the extraction process and the subsequent homogenization process in the present study did not change the crystalline structure of the cellulose fibres.

The crystallinity degrees of all samples were obtained by analyzing the X-ray diffractograms after deconvolution, which is shown in Fig. 11. It is evident that the $\mathrm{CrI} \%$ of 0 pass sample was of approximately $53 \%$ and increased to $57 \%$ after a single homogenisation step. A similar trend has been reported for cellulose crystallinity processed using various mechanical processes (e.g. grinding and high intensity sonication) (Tanpichai et al. 2019). However, the figure also indicates that as the number of passes increased, the crystallinity index was slightly decreased (55\% for 5 pass sample). Such a reduction of $\mathrm{CrI} \%$ can be attributed to the shear and impact

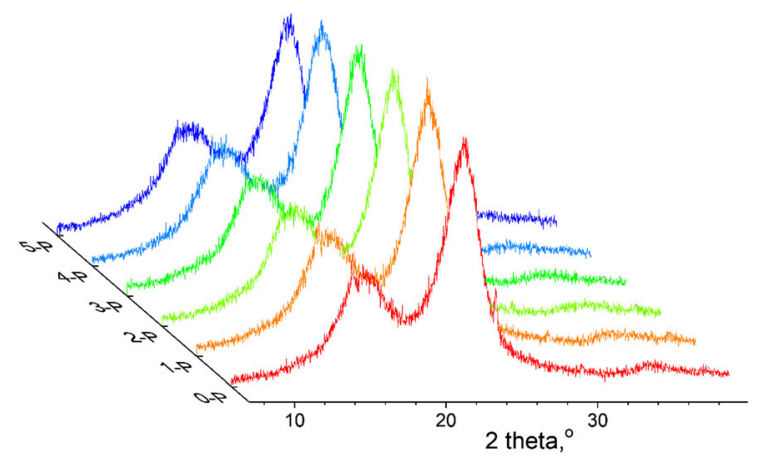

Fig. $10 \mathrm{X}$-ray diffraction patterns for the WH cellulose and the WH-CNFs from 1 to 5 passes 


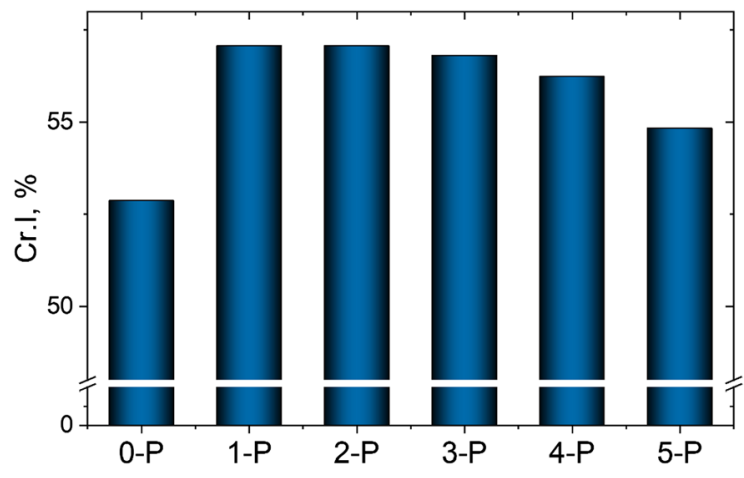

Fig. 11 Crystallinity degrees of the WH cellulose and WHCNF samples

forces applied during the homogenization process, which might slightly destruct the crystal region of cellulose fibres, causing a reduction of crystallinity (dos Santos et al. 2013; Nobuta et al. 2016).

Effects of processing degree on the tensile strength of WH cellulose films

The tensile strength of films for various samples are shown in Fig. 12. The tensile strength of WH film increased by up to $50 \%$ after 1 pass through the highpressure homogeniser. As observed from FE-SEM image analysis, the 0 pass sample contains large and heterogeneous fibres. During the fibrillation process, the aggregated course fibres were gradually broken down, forming a network of fibres/fibrils of smaller

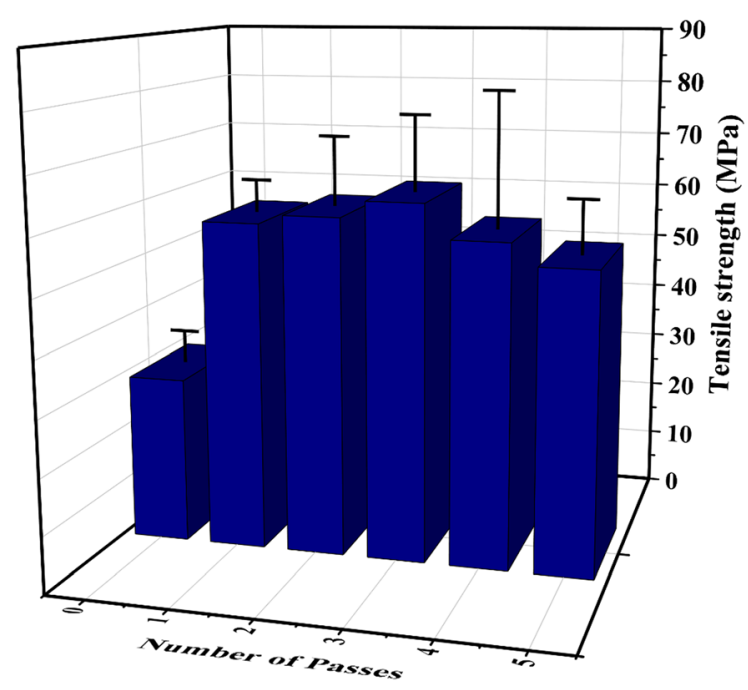

Fig. 12 Effect of the number of passes through the highpressure homogeniser on the tensile strength of WH films sizes, which led to the improvement of tensile strength of the film.

However, there was no significant increase in tensile strength from the second pass to the third pass. This behaviour does not correlate with those identified for WH cellulose suspensions analysed using rheometry and WRV methods. It should be noted that films that have undergone more than 2 passes, compared with those from 0 pass and 1 pass, were very brittle and showed significant crinkle upon drying. Several jaw breaks were found during the test for these samples which could contribute to the substantial variety of the results. The lower tensile strength values for the 4 pass and 5 pass samples could be because of the above reason, or the production of shorter fibrils by the extra homogenisation process. As the number of passes increases, both the diameter, length and crystallinity index of fibrils were reduced, transforming the film structure from a network of long overlapping fibrils into one that contain more discrete small individual fibrils, having reduced stress transfer ability (Rusli et al. 2011).

\section{Thermogravimetric analysis (TGA)}

Thermal stability studies on cellulose materials are essential if the materials are to be applied in high temperature formulations, melt compounding of polymers and composites (Qua et al. 2011; Onyianta et al. 2018a). An overlay of the TGA and derivative thermogravimetric (DTG) curves from the extracted WH cellulose (WH-OP) and processed samples (WH-

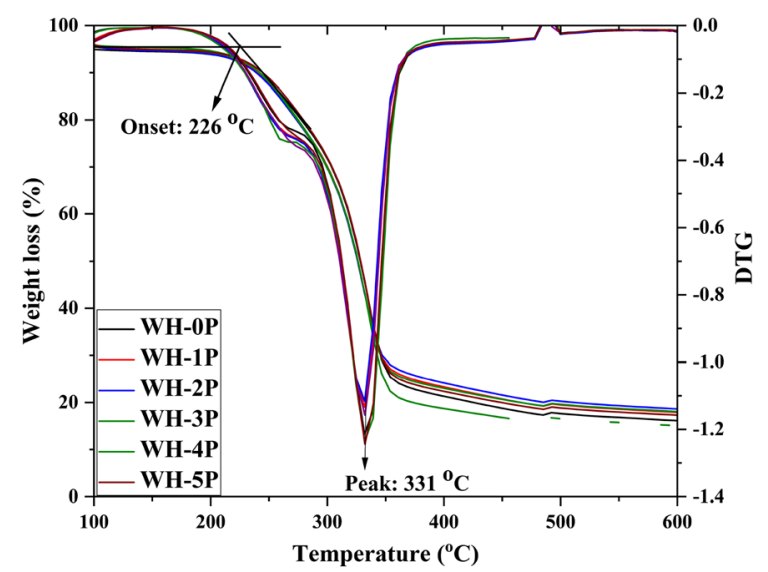

Fig. 13 TGA and DTG overlay of thermograms from extracted WH cellulose and processed WH-CNFs 
1P to 5P) are shown in Fig. 13. The initial weight loss occurring below $100{ }^{\circ} \mathrm{C}$ because of moisture desorption was not included in the TGA and DTG thermograms.

It can be seen from both thermograms that the mechanical shearing process did not affect the thermal stability of the WH-CNF. Mechanical shearing force does not affect the thermal stability of CNF materials to high degrees in comparison to chemical pretreatments used on cellulose to assist fibrillation, such as carboxymethylation and 2,2,6,6-tetramethylpiperidine-1-oxyl (TEMPO)-mediated oxidation (Eyholzer et al. 2010; Onyianta et al. 2018b). The onset degradation temperature for all the WH samples is $226{ }^{\circ} \mathrm{C}$ while the peak degradation is $331{ }^{\circ} \mathrm{C}$ as shown on the TGA and DTG curves respectively. This implies that WH-CNF can maintain its thermal stability when used as reinforcements in bioplastics like polylactic acid (PLA), which melt between 150 and $200{ }^{\circ} \mathrm{C}$ (Signori et al. 2009).

\section{Conclusions}

The mild homogenisation of water hyacinth stems resulted in the facile extraction of cellulose material under ambient conditions and mild chemical processing. Functional group analysis showed that the extracted cellulose becomes purer with successive chemical treatments. Significant increases in the morphological properties, water retention values and linear viscoelastic properties were observed with increase in number of passes, up to the third pass. Further increases in the degree of processing did not yield large increase in material properties that is commensurate with the additional energy input. Up to $7.5 \%$ and $50 \%$ increase in crystallinity index and tensile strength were observed for 1 pass WH cellulose material in comparison to the unprocessed cellulose. Therefore, as far as the cost effectiveness is concerned, it is believed that 1 cycle of homogenisation process is sufficient and practical for preparing films that could find application in packaging materials using this feedstock. Considering the good morphological property, viscoelastic properties and thermal properties, the cellulose nanomaterial from this study can also find application as reinforcing material and as structuring material in composite formulations.
Acknowledgments The authors would like to thank School of Engineering and Built Environment, Edinburgh Napier University who funded the work presented in this paper.

Open Access This article is licensed under a Creative Commons Attribution 4.0 International License, which permits use, sharing, adaptation, distribution and reproduction in any medium or format, as long as you give appropriate credit to the original author(s) and the source, provide a link to the Creative Commons licence, and indicate if changes were made. The images or other third party material in this article are included in the article's Creative Commons licence, unless indicated otherwise in a credit line to the material. If material is not included in the article's Creative Commons licence and your intended use is not permitted by statutory regulation or exceeds the permitted use, you will need to obtain permission directly from the copyright holder. To view a copy of this licence, visit http://creativecommons.org/licenses/by/4.0/.

\section{References}

Alemdar A, Sain M (2008) Isolation and characterization of nanofibers from agricultural residues-wheat straw and soy hulls. Bioresour Technol 99:1664-1671. https://doi. org/10.1016/j.biortech.2007.04.029

Al-khateeb IKI, Hussin SM, Al-obaidi YM (2015) Extraction of cellulose nano crystalline from cotton by ultrasonic and its morphological and structural characterization. Int J Mater Chem Phys 1:99-109

Asrofi M, Abral H, Kasim A et al (2018) Isolation of nanocellulose from water hyacinth fiber (WHF) produced via digester-sonication and its characterization. Fibers Polym 19:1618-1625. https://doi.org/10.1007/s12221-018-79531

Chen W, Yu H, Liu Y et al (2011) Isolation and characterization of cellulose nanofibers from four plant cellulose fibers using a chemical-ultrasonic process. Cellulose 18:433-442. https://doi.org/10.1007/s10570-011-9497-z

Cheng Q, Wang J, McNeel JF, Jacobson PM (2010) Water retention value measurements of cellulosic materials using a centrifuge technique. BioResources 5:1945-1954

Cherian BM, Pothan LA, Nguyen-Chung T et al (2008) A novel method for the synthesis of cellulose nanofibril whiskers from banana fibers and characterization. J Agric Food Chem 56:5617-5627. https://doi.org/10.1021/jf8003674

Cherian BM, Leão AL, de Souza SF et al (2010) Isolation of nanocellulose from pineapple leaf fibres by steam explosion. Carbohydr Polym 81:720-725. https://doi.org/10. 1016/j.carbpol.2010.03.046

Chinga-Carrasco G (2011) Cellulose fibres, nanofibrils and microfibrils: the morphological sequence of MFC components from a plant physiology and fibre technology point of view. Nanoscale Res Lett 6:1-7. https://doi.org/10.1186/ 1556-276X-6-417

Chung C, Lee M, Choe EK (2004) Characterization of cotton fabric scouring by FT-IR ATR spectroscopy. Carbohydr Polym 58:417-420. https://doi.org/10.1016/j.carbpol. 2004.08.005 
Dai D, Fan M, Collins P (2013) Fabrication of nanocelluloses from hemp fibers and their application for the reinforcement of hemp fibers. Ind Crops Prod 44:192-199. https:// doi.org/10.1016/j.indcrop.2012.11.010

dos Santos RM, Flauzino Neto WP, Silvério HA et al (2013) Cellulose nanocrystals from pineapple leaf, a new approach for the reuse of this agro-waste. Ind Crops Prod 50:707-714. https://doi.org/10.1016/j.indcrop.2013.08. 049

Eyholzer C, Bordeanu N, Lopez-Suevos F et al (2010) Preparation and characterization of water-redispersible nanofibrillated cellulose in powder form. Cellulose 17:19-30. https://doi.org/10.1007/s10570-009-9372-3

Fareez IM, Ibrahim NA, Wan Yaacob WMH et al (2018) Characteristics of cellulose extracted from Josapine pineapple leaf fibre after alkali treatment followed by extensive bleaching. Cellulose 25:4407-4421. https://doi. org/10.1007/s10570-018-1878-0

Guna V, Ilangovan M, Anantha Prasad MG, Reddy N (2017) Water hyacinth: a unique source for sustainable materials and products. ACS Sustain Chem Eng 5:4478-4490. https://doi.org/10.1021/acssuschemeng.7b00051

Gunnarsson CC, Petersen CM (2007) Water hyacinths as a resource in agriculture and energy production: a literature review. Waste Manag 27:117-129. https://doi.org/10. 1016/J.WASMAN.2005.12.011

Hermans PH, Weidinger A (1948) Quantitative x-ray investigations on the crystallinity of cellulose fibers. A background analysis. J Appl Phys 19:491-506. https://doi.org/ 10.1063/1.1698162

Hon DNS (1994) Cellulose: a random walk along its historical path. Cellulose 1:1-25. https://doi.org/10.1007/ BF00818796

Hu Y, Tang L, Lu Q et al (2014) Preparation of cellulose nanocrystals and carboxylated cellulose nanocrystals from borer powder of bamboo. Cellulose 21:1611-1618. https:// doi.org/10.1007/s10570-014-0236-0

Istirokhatun T, Rokhati N, Rachmawaty R et al (2015) Cellulose isolation from tropical water hyacinth for membrane preparation. Procedia Environ Sci 23:274-281. https://doi. org/10.1016/j.proenv.2015.01.041

Johar N, Ahmad I, Dufresne A (2012) Extraction, preparation and characterization of cellulose fibres and nanocrystals from rice husk. Ind Crops Prod 37:93-99. https://doi.org/ 10.1016/j.indcrop.2011.12.016

Jonoobi M, Oladi R, Davoudpour Y et al (2015) Different preparation methods and properties of nanostructured cellulose from various natural resources and residues: a review. Cellulose 22:935-969. https://doi.org/10.1007/ s10570-015-0551-0

Juárez-Luna GN, Favela-Torres E, Quevedo IR, Batina N (2019) Enzymatically assisted isolation of high-quality cellulose nanoparticles from water hyacinth stems. Carbohydr Polym 220:110-117. https://doi.org/10.1016/J. CARBPOL.2019.05.058

Karimi S, Tahir PM, Karimi A et al (2014) Kenaf bast cellulosic fibers hierarchy: a comprehensive approach from micro to nano. Carbohydr Polym 101:878-885. https://doi.org/10. 1016/j.carbpol.2013.09.106

Klemm D, Cranston ED, Fischer D et al (2018) Nanocellulose as a natural source for groundbreaking applications in materials science: today's state. Mater Today 21:720-748. https://doi.org/10.1016/j.mattod.2018.02.001

Lavoine N, Desloges I, Dufresne A, Bras J (2012) Microfibrillated cellulose-its barrier properties and applications in cellulosic materials: a review. Carbohydr Polym 90:735-764. https://doi.org/10.1016/j.carbpol.2012.05. 026

Li Y, Liu Y, Chen W et al (2016) Facile extraction of cellulose nanocrystals from wood using ethanol and peroxide solvothermal pretreatment followed by ultrasonic nanofibrillation. Green Chem 18:1010-1018

Luzi F, Fortunati E, Puglia D et al (2014) Optimized extraction of cellulose nanocrystals from pristine and carded hemp fibres. Ind Crops Prod 56:175-186. https://doi.org/10. 1016/j.indcrop.2014.03.006

Mandal A, Chakrabarty D (2011) Isolation of nanocellulose from waste sugarcane bagasse (SCB) and its characterization. Carbohydr Polym 86:1291-1299. https://doi.org/ 10.1016/j.carbpol.2011.06.030

Mendoza DJ, Browne C, Raghuwanshi VS et al (2019) One-shot TEMPO-periodate oxidation of native cellulose. Carbohydr Polym 226:115292. https://doi.org/10.1016/j.carbpol. 2019.115292

Nechyporchuk O, Belgacem MN, Pignon F (2014) Rheological properties of micro-/nanofibrillated cellulose suspensions: wall-slip and shear banding phenomena. Carbohydr Polym 112:432-439. https://doi.org/10.1016/j.carbpol.2014.05. 092

Nechyporchuk O, Belgacem MN, Pignon F (2016) Current progress in rheology of cellulose nanofibril suspensions. Biomacromolecules 17:2311-2320. https://doi.org/10. 1021/acs.biomac.6b00668

Nishiyama Y (2009) Structure and properties of the cellulose microfibril. J Wood Sci 55:241-249. https://doi.org/10. 1007/s10086-009-1029-1

Nobuta K, Teramura H, Ito $\mathrm{H}$ et al (2016) Characterization of cellulose nanofiber sheets from different refining processes. Cellulose 23:403-414. https://doi.org/10.1007/ s10570-015-0792-y

Onyianta AJ (2019) Surface functionality in nanocellulose processing and composite formulations. Edinburgh Napier University, Edinburgh

Onyianta AJ, Castellano M, Dorris M et al (2018a) The effects of morpholine pre-treated and carboxymethylated cellulose nano fibrils on the properties of alginate-based hydrogels. Carbohydr Polym 198:320-327. https://doi.org/ 10.1016/j.carbpol.2018.06.084

Onyianta AJ, Dorris M, Williams RL (2018b) Aqueous morpholine pre-treatment in cellulose nanofibril (CNF) production: comparison with carboxymethylation and TEMPO oxidisation pre-treatment methods. Cellulose 25:1047-1064. https://doi.org/10.1007/s10570-017-16310

Osong SH, Norgren S, Engstrand P (2016) Processing of woodbased microfibrillated cellulose and nanofibrillated cellulose, and applications relating to papermaking: a review. Cellulose 23:93-123. https://doi.org/10.1007/s10570-0150798-5

Pääkko M, Ankerfors M, Kosonen H et al (2007) Enzymatic hydrolysis combined with mechanical shearing and highpressure homogenization for nanoscale cellulose fibrils and 
strong gels. Biomacromolecules 8:1934-1941. https://doi. org/10.1021/bm061215p

Popescu CM, Popescu MC, Singurel G et al (2007) Spectral characterization of eucalyptus wood. Appl Spectrosc 61:1168-1177. https://doi.org/10.1366/ 000370207782597076

Popescu CM, Larsson PT, Olaru N, Vasile C (2012) Spectroscopic study of acetylated kraft pulp fibers. Carbohydr Polym 88:530-536. https://doi.org/10.1016/j.carbpol. 2011.12.046

Qua EH, Hornsby PR, Sharma HSS, Lyons G (2011) Preparation and characterisation of cellulose nanofibres. J Mater Sci 46:6029-6045. https://doi.org/10.1007/s10853-011-5565$\mathrm{x}$

Rahimi Kord Sofla M, Batchelor W, Kosinkova J et al (2019) Cellulose nanofibres from bagasse using a high speed blender and acetylation as a pretreatment. Cellulose 26:4799-4814. https://doi.org/10.1007/s10570-01902441-w

Reddy KR, Debusk WF (1984) Growth characteristics of aquatic macrophytes cultured in nutrient-enriched water: I. Water hyacinth, water lettuce, and pennywort. Econ Bot 38:229-239. https://doi.org/10.1007/BF02858838

Rusli R, Shanmuganathan K, Rowan SJ et al (2011) Stress transfer in cellulose nanowhisker composites-influence of whisker aspect ratio and surface charge. Biomacromolecules 12:1363-1369. https://doi.org/10.1021/ bm200141x

SCAN-CM 65:02 (2002) Total acidic group content. In: Scand. pulp, Pap. board Test. Comm. http://www.kemesta.fi/ document.php/1/102/cm_65-02.pdf/ cf67249808953749768b08f7e2eb88af. Accessed 19 Mar 2019

Shogren RL, Peterson SC, Evans KO, Kenar JA (2011) Preparation and characterization of cellulose gels from corn cobs. Carbohydr Polym 86:1351-1357. https://doi.org/10. 1016/j.carbpol.2011.06.035

Signori F, Coltelli M-B, Bronco S (2009) Thermal degradation of poly(lactic acid) (PLA) and poly(butylene adipate-coterephthalate) (PBAT) and their blends upon melt processing. Polym Degrad Stab 94:74-82. https://doi.org/10. 1016/J.POLYMDEGRADSTAB.2008.10.004

Siró I, Plackett D (2010) Microfibrillated cellulose and new nanocomposite materials: a review. Cellulose 17:459-494. https://doi.org/10.1007/s10570-010-9405-y

Someshwar AV, Pinkerton J (1992) Wood processing industry. Air Pollution Engineering Manual, Air and Waste
Management Association. Van Nostrand Reinhold, New York, pp 835-849

Song Y, Jiang W, Zhang Y et al (2018) A novel process of nanocellulose extraction from kenaf bast. Mater Res Express. https://doi.org/10.1088/2053-1591/aac80d

Spence KL, Venditti RA, Rojas OJ et al (2011) A comparative study of energy consumption and physical properties of microfibrillated cellulose produced by different processing methods. Cellulose 18:1097-1111. https://doi.org/10. 1007/s10570-011-9533-z

Srivastava LM (2002) Cell wall, cell division, and cell growth. In: Plant growth and development, pp 23-74

Suryadi H, Sari HR, Rosikhoh D (2017) Preparation of microcrystalline cellulose from water hyacinth powder by enzymatic hydrolysis using cellulase of local isolate. J Young Pharm. https://doi.org/10.5530/jyp.2017.1s.6

Tanpichai S, Biswas SK, Witayakran S, Yano H (2019) Water hyacinth: a sustainable lignin-poor cellulose source for the production of cellulose nanofibers. ACS Sustain Chem Eng 7:18884-18893. https://doi.org/10.1021/acssuschemeng. 9b04095

Tarchoun AF, Trache D, Klapötke TM et al (2019) Ecofriendly isolation and characterization of microcrystalline cellulose from giant reed using various acidic media. Cellulose 26:7635-7651. https://doi.org/10.1007/s10570-01902672-x

Theivasanthi T, Anne Christma FL, Toyin AJ et al (2018) Synthesis and characterization of cotton fiber-based nanocellulose. Int J Biol Macromol 109:832-836. https:// doi.org/10.1016/j.ijbiomac.2017.11.054

Thiripura Sundari M, Ramesh A (2012) Isolation and characterization of cellulose nanofibers from the aquatic weed water hyacinth-Eichhornia crassipes. Carbohydr Polym 87:1701-1705. https://doi.org/10.1016/J.CARBPOL.2011. 09.076

Tibolla H, Pelissari FM, Martins JT et al (2018) Cellulose nanofibers produced from banana peel by chemical and mechanical treatments: characterization and cytotoxicity assessment. Food Hydrocoll 75:192-201. https://doi.org/ 10.1016/J.FOODHYD.2017.08.027

Publisher's Note Springer Nature remains neutral with regard to jurisdictional claims in published maps and institutional affiliations. 